\title{
TURISMO NA ERA ON-LINE: UM ESTUDO SOBRE E-MARKETING EM AGÊNCIAS DE VIAGENS DE NATAL/RN.
}

\author{
R. M. ARAÚJO' , A. M. SILVA ${ }^{2}$, R. S. C. CHRISTO ${ }^{3}$ \\ 1 Professor da FACEX e Doutorando em Administração pelo PPGA/UFRN - richardmaraujo@uol.com.br \\ ${ }^{2}$ Bacharel em Turismo pela FACEX - alexander.designer@hotmail.com \\ ${ }^{3}$ Professor da FACEX e Mestre em Administração pela UnP - rodrigochristo@yahoo.com.br
}

Artigo submetido em abril/2012 e aceito em julho/2012

\section{RESUMO}

Este artigo Procura traçar um perfil quanto ao uso do $E$ marketing pelas agências de turismo em Natal/RN, fazendo uma análise da tecnologia utilizada para comunicação do produto turístico no contexto mercadológico, visando uma melhor organização dos procedimentos a serem adotados para o desenvolvimento e planejamento de ações promocionais de vendas e para fins de segmentação na comunicação de ofertas, criarem consciência da marca e fidelizar o consumidor lançando seus produtos com tecnologias inovadoras disponibilizadas para demonstrar as novas formas e possibilidades de desenvolver ações, visando estreitar o relacionamento com seu público-alvo e ampliar o mercado. A metodologia teve caráter quantitativo, composta por uma pesquisa bibliográfica exploratória-descritiva, tendo como base 10 (dez) agências de médio e grande porte da cidade Natal/RN, cadastradas na JUNCERN/RN. Os resultados apontaram que as informações de clientes das empresas analisadas são utilizadas para planejar ações promocionais de vendas e comunicação dirigida, evidenciando a preocupação em segmentar ações, possibilitada pelo marketing digital. Foram identificadas, oportunidades para uso de nível mais estratégico e voltado para o estreitamento da relação com os clientes, mostrando a realidade atual das empresas e o retorno alcançado quando a ferramenta desempenha papel primordial na difusão da imagem e no fechamento de mais negócios

PALAVRAS-CHAVE: Marketing Turístico, Marketing Eletrônico, Agências de Turismo.

\section{TOURISM WAS ON-LINE: A STUDY OF E-MARKETING IN TRAVEL AGENCIES IN NATAL / RN}

\begin{abstract}
This paper looks to trace a profile related to the usage of E-marketing by tourism agencies on Natal/RN, making an analysis of the technology used for the tourism product communication in the marketing context, aiming for a better organization procedures to be adopted for the development and promotional actions planning of sales and for purposes of segmentation in communication offers, to originate the brand sense and make a loyalty with the consumer releasing your products with innovative technologies available to demonstrate the new forms and possibilities of actions development, aiming to shorten the relationship with your target audience and expand the market. The methodology had a quantitative feature, made by a
\end{abstract}

descriptive exploratory bibliographic research, having as base 10 (ten) agencies of medium and large size from the city of Natal/RN, registered in the JUNCERN/RN. The results pointed that the clients information from the Companies that were analyzed are used for planning promotional actions of sales and directed communication, showing the concern in target stock, possible by the digital marketing. There were identified, opportunities for the usage of an strategic higher level and turned to the narrowing of the relationship with clients, showing the actual reality of companies and the return achieved when the tool plays the primary role in the diffusion of image and in the closing of more business.

KEY-WORDS: Tourism Marketing, Electronic Marketing, Travel Agencies. 


\section{TURISMO NA ERA ON-LINE: UM ESTUDO SOBRE E-MARKETING EM AGÊNCIAS DE VIAGENS DE NATAL/RN.}

\section{Introdução}

Grandes empresas na atualidade usam o comércio eletrônico em busca de facilidades para a comercialização de produtos ou serviços que possam satisfazer os desejos e as necessidades do consumidor. A Internet disseminou inovações de software e hardware desenvolvidos especificamente para oferecer oportunidades de realização de negócios on-line. Paralelamente, a competição no varejo virtual tem se acirrado, com isso, a tarefa de conquistar e manter clientes tornou-se mais competitiva.

O Marketing Eletrônico (Eletronic Marketing) e Gestão Eletrônica de Relacionamento com o Consumidor (E-CRM) passaram então a apresentar-se como ferramentas que tem por desígnio unir as práticas de negócio modernas com a inovação tecnológica.

Baseando-se nas informações acima, esse artigo tem como objetivo principal analisar de que maneira as agências de viagem da cidade de Natal/RN utilizam-se de tais ferramentas para aperfeiçoar o fluxo das vendas do produto turístico bem como, diagnosticar quais os produtos e recursos são mais oferecidos aos clientes e aos prospects, compreendendo como a gestão do marketing incorpora as práticas de ações digitais.

Diante disso, foi realizada uma revisão de literatura abordando os temas tais com: "Comércio Eletrônico" e "Relacionamento com o Cliente", com ênfase no uso do CRM (Customer Relationship Management) em varejo virtual.

A inovação tecnológica no mundo da web no ramo empresarial de agências de viagens já é uma realidade perceptível. Novas formas de negócios estão surgindo em função de novas mídias e peculiaridades promovidas pela Internet. Sendo assim, essa proposta obtém relevância acadêmica, pois fomenta a discussão da relação entre turismo e marketing eletrônico.

Diante desse universo, considerando o Rio Grande do Norte como um Estado turístico, deve-se compreender como a ascensão do turismo virtual vem se apresentando como intermediador de serviços turísticos operados na grande rede, seja na tentativa de criar consciência da marca, seja visando meios de estreitar o relacionamento com o seu público, ou seja, para ampliar o seu mercado utilizando-se de meios como:

- Internet (conjunto de documentos multimídia armazenados em computadores de todo o mundo);

- Orkut ( rede social responsável pelo compartilhamento de idéias entre pessoas e que possuem interesses e objetivos em comum);

- E-mail Marketing (iniciativa a partir da ação proposta no e-mail) entre outros, podendo demonstrar as possibilidades de sucesso como ferramenta de negócio e relacionamento.

Assim, o enfoque deste artigo será a de buscar responder a seguinte questão problema: como as maiores agências de viagens em Natal/RN utilizam as práticas de marketing na web. Algumas indagações secundárias nortearam esse estudo: Qual o perfil das agências de viagens de Natal/RN? Quais são as estratégias de $E$ - marketing utilizadas? Quais são as táticas e tecnologias usadas na comunicação? Que tipos de informações são utilizados para aperfeiçoar o fluxo nas vendas e na manutenção do relacionamento? 


\section{Referencial Teórico}

\subsection{Turismo e agência de viagem}

Existem duas linhas de pensamentos, nas quais a História do Turismo se divide. A primeira seria que o Turismo se inicia no Século XIX como deslocamento, cuja finalidade principal é o ócio, descanso, cultura, saúde, negócios ou relações familiares. Estes deslocamentos se distinguem por sua finalidade dos outros tipos de viagens motivados por guerras, movimentos migratórios, conquista, comércio etc. Depois, se concretizaria com o então movimento da Revolução Industrial. A segunda linha de pensamento defende que o Turismo realmente se iniciou com a Revolução Industrial, visto que os deslocamentos tinham como objetivo maior o lazer (BENI, 1998).

No século XIX, Thomas Cook iniciou a comercialização do turismo e com ele surgiu, as primeiras empresas do ramo. $O$ turismo passa a ganhar cada vez mais adeptos face às inovações trazidas pela Revolução Industrial, não só no campo tecnológico, mais também político, econômico e social. $\mathrm{O}$ aparecimento do trem e da máquina a vapor começou a criar condições mais favoráveis às viagens em escala acelerada. Cook programou várias viagens em grupos e com total sucesso. Viagens em grupo que, nas últimas décadas do século $X X$, através de tarifas especiais, vêm movimentando milhares de turistas. Além de Cook, cabe também mencionar dois outros grandes comercializadores do turismo: o inglês Thomas Bennet e o alemão Louis Stangen (CASTELLI, 1996).

A história do turismo começa há milhares de anos, com os gregos e romanos (idade antiga). Apenas recentemente, com o advento do turismo de massa, a atividade internacional tornou-se tão predominante no mundo desenvolvido. Desde os anos 60 (século XX) houve uma rápida expansão de viagens de lazer, precipitada pela evolução dos transportes, que continua até hoje em todos os aspectos do sistema de turismo (GOELDNER; RITCHE; MCINTOSH, 2002).

\footnotetext{
Turismo pressupõe a dimensão de uma conquista do espaço por pessoas que aluem a uma determinada localidade (cidade, estado, país, continente), onde não buscam fixar ou estabelecer residência. Assim, o turismo caracterizava-se pela soma das relações existentes entre as pessoas que se encontram passageiramente em uma localidade, que seria o núcleo receptor, e os habitantes (CRISÓSTOMO, 2004, p.16).
}

Levando em consideração, o ano de 1945 como sendo o ano em que se iniciou o maior crescimento da indústria do turismo, é possível fazer algumas observações gerais com relação às mudanças que podem ser identificadas no setor. Antes da década de 1950, o turismo era um tipo de indústria fragmentada; operadores de transporte, agências de viagens e operadoras de turismo, a tendência era trabalhar de forma independente entre si. A atividade dos hotéis consistia, em sua maioria, na venda de quartos. A atividade das empresas aéreas e ferroviárias consistia na venda de assentos. As agências de viagens, obviamente, vendiam viagens e pacotes, mas, em ambos os casos, tendiam a operar isoladamente. A partir de meados da década de 1950, principalmente no Reino Unido, o aumento do número de agências-operadoras modificou a 
natureza da indústria, que passou de uma atividade essencialmente individual para uma atividade mais integrada (LICKORISH; JENKINS, 2000).

A demanda turística e a mudança em algumas variáveis, inevitavelmente, influenciaram o desenvolvimento demográfico, político e tecnológico previsíveis, fora da atividade turística, juntamente com os efeitos de variáveis específicas do turismo, como pacotes turísticos criativos, preferências dos consumidores e evoluções nos transportes, que continuaram a influenciar todos os aspectos do sistema (GOELDNER; RITCHE; MCINTOSH, 2002).

Os mesmos autores complementam afirmando que

O turismo pode ser definido como a soma de fenômenos e relações originados da interação de turistas, empresas, governos locais e comunidades anfitriãs, no processo de atrair e receber turistas e outros visitantes (GOELDNER; RITCHE; MCINTOSH, 2002, p.23).

A partir disso, tem-se medido o impacto econômico do turismo desde 1991. Em 1992, foram lançadas as primeiras avaliações sobre o impacto econômico do turismo e suas viagens no mundo, nas regiões e nos países, indicando que a atividade é um das maiores do mundo e uma geradora de empregos de qualidade (FOSTER, 1992).

Na visão de Lickorish e Jenkins (2000), com a tendência da globalização há grupos diferentes de pessoas viajando para distâncias cada vez maiores. À medida que as pessoas se tornam viajantes mais sofisticados, a indústria de viagens vai se adaptando para atender as necessidades individuais.

No entanto, estes rendimentos diretos ocasionam um movimento acrescido em todas as atividades comerciais relacionadas. Isto aumenta os rendimentos do governo (impostos) e o rendimento de famílias como membros que trabalham no turismo e outras indústrias relacionadas, sobretudo os transportes, algumas atividades culturais, lembranças, etc (CASTELLI, 1996).

Percebe-se na relação turismo, transações comerciais e de negócios através de redes de computadores, especificamente a compra e a venda de produtos e serviços (FIORE, 2001). Hoje as mudanças estruturais não são feitas somente em ativos tangíveis, como marcas, relacionamento com o cliente, integração com o fornecedor e agregação flexível de ativos-chave e-business, a informação em torno do produto ou serviço é mais importante que o produto ou serviço em si (KALAKOTA; ROBINSON, 2001).

Frente a esse quadro uma agência de viagens é uma empresa que trabalha como intermediária entre seus clientes e determinados prestadores de serviços turísticos (Empresas aéreas, hotéis, cruzeiros), oferta e demanda, onde realiza a função de comercialização da oferta turística. Com o objetivo de vender produtos e serviços relacionados com essas viagens a um preço e com determinadas condições especialmente atrativas em relação com as que se poderia conseguir ao dirigir-se diretamente a esses provedores (REJOWSKI, 2001).

O Marketing Eletrônico tem como mais uma oportunidade de as agências estarem presentes na vida de seu público tanto quanto forem solicitadas pelos mesmos. A popularização 
da venda on-line está em consonância com a necessidade de se organizar o volume de informações disponíveis na Internet que cresce exponencialmente. E o marketing surge como mais uma modalidade de negócios que articula a necessidade de informações do internauta com a conveniência das vendas digitais. Katherine (2012) observa que diversos elementos são considerados no processo de compra digital, dentre ele o desing da página e suas funcionalidades que devem convergir para um cenário cuja a diretriz estratégica deve convergir com a facilitação do acesso, navegação e propensão à compra.

\subsection{Internet}

Desenvolvido pelo Instituto de Pesquisas Militares Norte-Americano, o sistema de transmissão de dados permitiu maior segurança das informações confidenciais pertencentes aos EUA, pois garantia a integridade dos conteúdos estratégicos e bancos de dados caso algum ataque acontecesse. Com o fim da Guerra Fria no início da década de 90, esse sistema de transmissão de informações direcionou-se para as Universidades Norte Americanas com o intuito de pesquisas acadêmicas e científicas. Com o passar dos anos e conseqüentemente com a popularização do recurso, a nomenclatura Internet surge e ultrapassa os limites militares e acadêmicos, chegando a outros segmentos da sociedade e outros países, principalmente ocidentais (BRUNNER; LELAND; HEYMAN, 2001).

No Brasil, a rede de comunicação chegou em 1989, via Fundação de Apoio à Pesquisa de São Paulo- FAPESP e a Universidade Federal do Rio de Janeiro (UFRJ), popularizando-se não mais como um canal bélico ou estritamente científico, mas como uma rede de comunicação funcional e um novo mercado para transações comerciais. A partir do ano de 1996, a Web caracterizou-se como uma rede comercial, havendo o surgimento de lojas com seu ponto de venda virtual e de empresas cujo investimento se deu do físico para o virtual. Com a ampliação dessa rede de computadores (Internet), surge a necessidade de profissionais preparados para essa realidade tecnológica e interacionista. No Brasil até o início do ano 2000, os profissionais que trabalhavam com esse recurso eram adaptados de outras áreas da tecnologia com formação nos cursos de Sistemas de Informação, Ciências da Computação, Engenharia da Computação e demais cursos na área de processamento de dados (KENDZERSKI, 2005).

Segundo Zenone (2008) a internet gera uma grande possibilidade para as empresas de interagir com os seus clientes a partir do momento que passa a ser reconhecida como mais um canal de relacionamento com o mercado-alvo e um meio de ofertar produtos e serviços. A internet permite criar uma facilidade e conveniência aos clientes, uma vez que os mesmos podem utilizar este canal para acessar as empresas, pesquisar e efetuar transações dentro das suas residências, demandando menos esforço e tempo. Como observa Lazaroiu (2010) os modelos de negócio devem ser construídos sobre uma plataforma de muitos processos ou funções. Modelos de negócios bem definidas que trazem a ênfase `a Internet aqueles que busca a adoção de comércio eletrônico leilões on-line e outros.

\subsubsection{Comércio eletrônico (e-commerce)}


O Comércio Eletrônico é um sistema de transações ou realizações de atividades comerciais e comunicações de negócios através de redes de computadores, relacionados especificamente a compra e a venda de produtos e serviços, e a transferência de fundos através de comunicações digitais (FIORE, 2001).

Hoje, as mudanças estruturais não são feitas somente em ativos tangíveis, como marcas, relacionamento com o cliente, integração com o fornecedor e agregação flexível de ativos-chave. O impacto do e-commerce na economia vai muito além transação eletrônica de bens e serviços. O desenvolvimento desta estratégia requer uma compreensão do negócio da empresa, do segmento do mercado que ela pretende atuar, das ferramentas digitais disponíveis, do conhecimento das formas de comunicação atuais e dos recursos disponíveis para este investimento. Oferecendo novas dimensões à comunicação digital e ao relacionamento com o mercado, isto é, através das "ferramentas" do e-marketing (KENDZERSKI, 2005), tais como:

- Interatividade: utilizando o e-mail marketing como uma ferramenta, uma via de duas mãos, é fundamental para o sucesso do projeto WEB;

- Personalização: através de um atendimento com uma excelente prestação de serviços e com custos operacionais baixos;

- Globalização: a empresa publica seu site na internet, deixando de ser local tornando-se global permitindo acesso de qualquer lugar do mundo, informações atualizadas e muito mais;

- Integração de diversos pontos, independente de sua localização, integrando de forma online filiais, parceiros e fornecedores em diferentes localidades, sejam no mesmo país ou no exterior;

- Aproximação à tecnologia multimídia permite a divulgação de produtos e serviços através de imagem, vídeo e áudio;

- Convergência: a junção em um só meio de imagem digitais, vídeo, som e texto abriram novos horizontes para setores de informação, entretenimento e serviços de comunicação;

- Democratização da informação pessoas com acesso à grande quantidade de informações. A distribuição de informação ficou acessível a um grande número de pessoas, independente de onde elas estão localizadas.

Deste modo, conhecer os clientes significa ter os dados disponíveis em todos os departamentos, ter a capacidade de analisar e finalmente transformar estes dados em informações úteis. A internet mudou a maneira como as pessoas trabalham e se relacionam com empresas, normalmente associados ao excesso de empolgação com a tecnologia superando objetivos estratégicos através destas ferramentas como aliados de comunicação, vendas, atendimento e conquista da fidelidade do cliente, pois o mercado está exigindo cada vez mais empresas que tenham essa visão de negócios (KENDZERSKI, 2005).

\subsubsection{Marketing eletrônico}


A Internet é a maior rede das redes de computadores do mundo, conectando dezenas de milhões de pessoas em mais de 160 países. Os participantes pertencem, virtualmente, a todas as faixas etárias e todos os estilos de vida. A globalização da telefonia ajudou a criar uma comunidade global, neste mesmo sentido a Internet está ajudando a criar uma aldeia global virtual, não só fornecendo uma infra-estrutura de envio e recebimento de mensagens e supervelocidades, mas também para troca de imagens, sons (incluindo voz), clipes de vídeos, dados eletrônicos e aplicativos de computador (BRUNNER, JENKINS e HEYMAN, 2001),

Segundo Brunner, Jenkins e Heyman, (2001) a sociedade global é uma vertente sociológica que permite a integração dos aspectos culturais e étnicos, sendo por conseqüência um efeito de interação do homem com os recursos tecnológicos.

Na visão de Reedy, Schullo e Zimmerman (2001, p.26) "através do comércio eletrônico grandes empresas são criadas, a prática de satisfazer os desejos e necessidades do consumidor através do comércio on-line para a ser uma exigência". Neste cenário de novas relações comerciais, as inovações de software e hardware facilitaram o comércio eletrônico bem como o processo do marketing eletrônico, desenvolvidos especificamente para oferecer conveniência às compras on-line, gerar satisfações e manutenção de relacionamentos. Juntamente com a internet, através de recursos como: pesquisa de consumidores, e-mail, sites, agentes inteligentes de compras, pesquisas de auto-identificação on-line, entre outras ferramentas eletrônicas, estão sendo integradas aos programas tradicionais de marketing, melhorando o alcance e a eficácia do contato com os públicos-alvos. O marketing on-line é uma extensão tática e estratégica de alta tecnologia pra coleta de informações, marketing direto e feedback de clientes, atividades essas muitas importantes da Comunicação Integrada de Marketing.

Para Van Dor e Enbreitenbach (1998) o comércio eletrônico deve caminhar como uma lógica de marketing digital, em que o ambiente virtual tem relações direta com o comportamento do consumidor, assim as organizações devem se dotar de instrumentais que fomentem uma busca pela permanência dos consumidores nas home pages. Dadas as forças e fraquezas inerentes da Internet, como um veículo de comunicação de marketing, o marketing eletrônico devem desenvolver técnicas para aproveitar as vantagens oferecidas pelos meios de comunicação da Internet. Estas técnicas devem fornecer um valor para o visitante, e fornecerIhes os serviços que não são facilmente replicadas pela mídia de marketing convencional. As técnicas também devem ser adaptadas para atender as necessidades e desejos dos visitantes do site típicas da Web, fornecendo-Ihes uma boa razão para visitar e uma razão ainda melhor para voltar.

Para Breintenbach e Van Doren (1998) e Kiani (1998) observam que as organizações devem:

a) No site poderia oferecer aos usuários a oportunidade de receber informações gratuitas por email sobre ofertas de uma empresa. Material recebido pode incluir brochuras, catálogos ou CDROMs contendo informações em formato multimídia.

b) A empresa poderia dedicar uma seção de sua homepage para notícias diárias sobre um determinado setor. Esta seção também pode incluir comunicados de imprensa sobre as 
inovações de produtos novos e descobertas feitas pela empresa. Os usuários podem valorizar esta informação e provavelmente iria lembrar do local onde se obteve.

c) A página inicial deve ajudar os usuários a identificar a localização de revendedores e lojas na área do usuário. Muitas empresas fazem casos convincentes para a compra de seus produtos na Web, mas esquecem de informar aos usuários onde eles poderiam comprar esses produtos. Qualquer página inicial deve incluir um número toll-free e pessoa a contactar para obter informações adicionais, o que poderia ser conseguido através do uso de uma página dedicada informações de contato.

d) A importância em sensibilizar os navegadores para quaisquer atividades de caridade, os esforços da comunidade, e projetos ambientais em que a empresa está envolvida. Os usuários podem ser mais inclinados a comprar produtos e serviços de empresas socialmente responsáveis. A empresa também pode optar por compartilhar a história de sua organização, bem como sua cultura fundamental.

e) A homepage da empresa deve fornecer mais informações detalhadas do produto, ou serviço atual disponível, uso de multimídia para obter as informações através de usuários. Esta informação deve estar disponível 24 horas por dia, sete dias por semana. A homepage também pode fornecer aos usuários ferramentas que lhes permitam pesquisar com facilidade para obter informações sobre algum aspecto de um determinado produto ou serviço. A chave é ter informação facilmente disponível para usuários com base em suas solicitações. Os usuários não devem ser sobrecarregadas com informações, eles devem ser capazes de obter as informações que eles precisam, quando eles querem, com o menor esforço possível.

f) Considerar nichos pequenos demais para ser servido com lucro hoje vai se tornar viável como melhorar a eficiência do marketing. Comunicações com alvos específicos e direcionaidos com precisão cada vez maior, e feedback sobre ações de marketing vai se tornar mais precisos.

\subsubsection{O CRM e a Tecnologia da Informação}

Segundo Zenone (2008), uma empresa ao utilizar O CRM (Customer Relationship Management), entende-se muito mais do que utilizar programas específicos alicerçados pela tecnologia da informação voltados para programas de fidelização ou call centers. Para o autor, compreende-se como uma estratégia de marketing orientada para criação de valor contínuo para os clientes e para a organização, no qual haverá um esforço corporativo, com o propósito de gerar em longo prazo um relacionamento estreito entre empresa e o cliente no qual ambos saiam concomitantemente satisfeitos neste processo. Desta forma, clientes mais satisfeitos potencializam seu consumo com a marca e por outro lado, a empresa ganha ao aumentar sua lucratividade. Evidencia-se, portanto, que o objetivo da utilização do CRM é aperfeiçoar e potencializar o relacionamento da organização com o seu mercado-alvo. Para Zenone (2008, p.65) esta atividade vem sendo facilitada a partir "da interação cada vez maior das estratégias de 
marketing e a tecnologia da informação, a qual vem permitindo às empresas promoverem meios de identificar, diferenciar, interagir e personalizar a relação com o cliente [...]".

Segundo Kotler e Keller (2006), é possível a partir dos dados coletados dos clientes a através do uso da tecnologia da informação, conhecer melhor as necessidades mais peculiares de cada cliente, permitindo assim, uma oferta de serviços e produtos mais direcionados e consequentemente gerando vínculos mais fortes e rentáveis com o mercado-alvo.

Para Zeithaml (2011) conforme a empresa aperfeiçoa (Figura 1) a forma de interagir com os seus clientes, os mesmos se tornarão mais envolvidos com a marca à medida que consumirão mais produtos e serviços e aumentarão sua participação na geração de receita para a empresa. Para o autor o principal desafio do marketing de relacionamento é construir e gerenciar a base dos clientes de tal forma que permita identificar e separar os clientes mais compromissados e rentáveis para a empresa, sendo assim, "o objetivo do marketing de relacionamento é fazer com que os clientes movam-se ao longo da escada: a aquisição de clientes, a satisfação dos clientes, a retenção e o aperfeiçoamento do relacionamento com os clientes" (ZEITHAML, 2011, p.217).

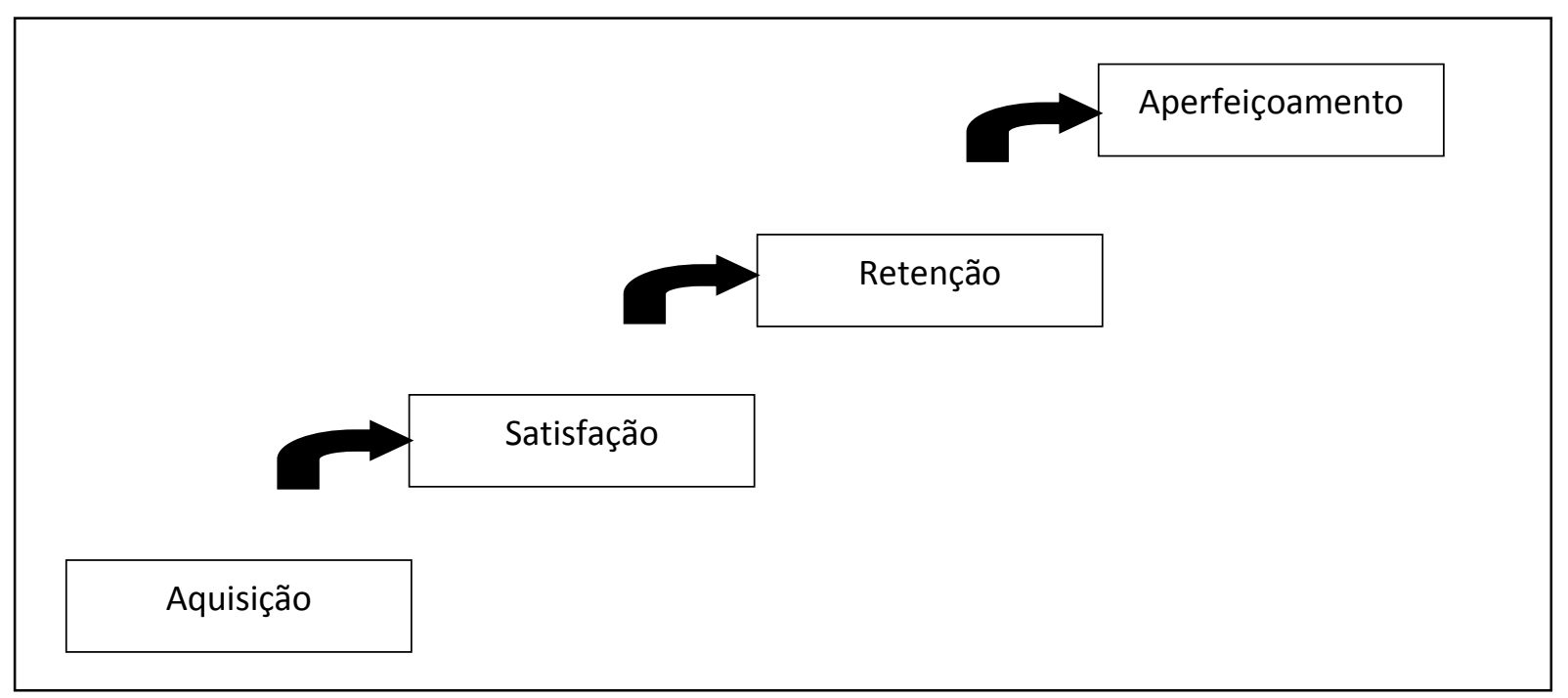

Figura 1: O objetivo do marketing de relacionamento

Fonte: Adaptado de Zeithaml (2011, p.217)

\section{Procedimentos Metodológicos}

O Método Quantitativo é muito utilizado no desenvolvimento das pesquisas descritivas, significa quantificar opiniões, dados, nas formas de coleta de informações, assim como também procura descobrir e classificar a relação entre variáveis, assim como na investigação da relação de causalidade entre os fenômenos (OLIVEIRA, 1999). Para Honorato (2004) a pesquisa quantitativa é adequada quando se pretende quantificar dados e aplicar alguma forma estatística para analisá-los. No estudo em tela a abordagem se caracteriza como quantitativa uma vez que se busca descrever como se materializam as praticas de marketing eletrônico das agencias de viagem que tem domínio próprio. 
Optou-se por uma combinação entre pesquisa bibliográfica e uma pesquisa exploratória descritiva. Utilizou-se o método de levantamento para examinar como agências de viagens estão utilizando as estratégias de marketing na web (MALHOTRA, 2004).

Para alcançar os objetivos da pesquisa, foi realizado um estudo de caso, contemplando uma amostra de dez (10) agências de viagens de grande porte de Natal/RN (selecionadas as que possuem o maior valor de capital social informado) cadastradas na Junta Comercial do Estado do $\mathrm{RN}$, todas com site na grande rede e domínio próprio.

A partir do quadro conceitual construído a partir da literatura estruturou-se o instrumento questionário. Este estava dotado de questões fechadas, subsidiado nos autores Brunner, Leland e Heyman (2001) e Fiore (2001) cujas variáveis de análise foram: ferramentas de marketing na web, percepções de usabilidade e identidade visual.

O questionário era composto com "33" questões de múltipla escolha, onde 4 trataram do perfil das agências, 19 buscou compreender o Conhecimento e Utilização de Ferramentas e Estratégias de E-Marketing nas Agências de Viagens e as 10 últimas questões tratavam da Grau de Concordância Relacionada ao Layout e a Usabilidade do Site As empresas foram previamente informadas pelo pesquisador, buscando autorização de envio dos e-mails, e após a autorização, estes foram direcionados às gerências de marketing das respectivas agências de viagens de Natal/RN. A amostra da pesquisa é de caráter não probabilítisca visto segundo Aaker (2010) e Honorato (2004), o processo de amostragem não utiliza uma seleção aleatória dos sujeitos entrevistados, sendo também intencional uma vez que consiste na escolha da amostra partindo do julgamento do pesquisador e nos critérios estabelecidos pelo mesmo. Portanto, o critério das empresas selecionadas pelos pesquisadores partiu do valor de capital social das organizações.

Segundo Andrade (2001) o questionário serve para elaborar as perguntas onde o informante não poderá contar com explicações adicionais do pesquisador, onde as perguntas devem ser muito claras e objetivas dando preferência ao emprego de perguntas fechadas, ou seja, as que pedem respostas curtas e previsíveis. Na primeira parte do instrumento estavam dispostas as afirmativas que variavam cujas respostas era sim, não ou não sabe informar". Já na segunda parte do instrumento, as variáveis se configuraram entre "muito importante" e "sem importância cujas as perguntas fechadas formuladas foram desenhadas a partir da escala Likert de cinco pontos". O terceiro bloco de questões eram dotados $d$ assertivas onde os sujeitos se posicionavam frente a escala Likert (de 5 pontos), que variava de concordo totalmente a discordo totalmente.

A coleta dos dados aconteceu durante o mês de novembro/2008, ressalte que o pesquisador não obteve dificuldade no retorno dos instrumentos. Os dados foram tratados através de planilhas com o software Excel. Adotou-se uma análise através de estatística descritiva tratando as variáveis por meio de porcentagens.

\section{Análise e discussão dos resultados}

A perspectiva neste momento é analisar os dados coletados na pesquisa de campo. A amostra investigada foi de 10 (dez) agências de viagens grande porte situadas em Natal/RN. 
Assim, serão apresentados a seguir os gráficos com as respectivas análises, discussões e interpretações.

Tempo de
Atuação
Total de
Funcionários
Faturamento
Investido em
Comunicação
Pacotes
Turísticos
Meios de
Implementação
do E-Marketing

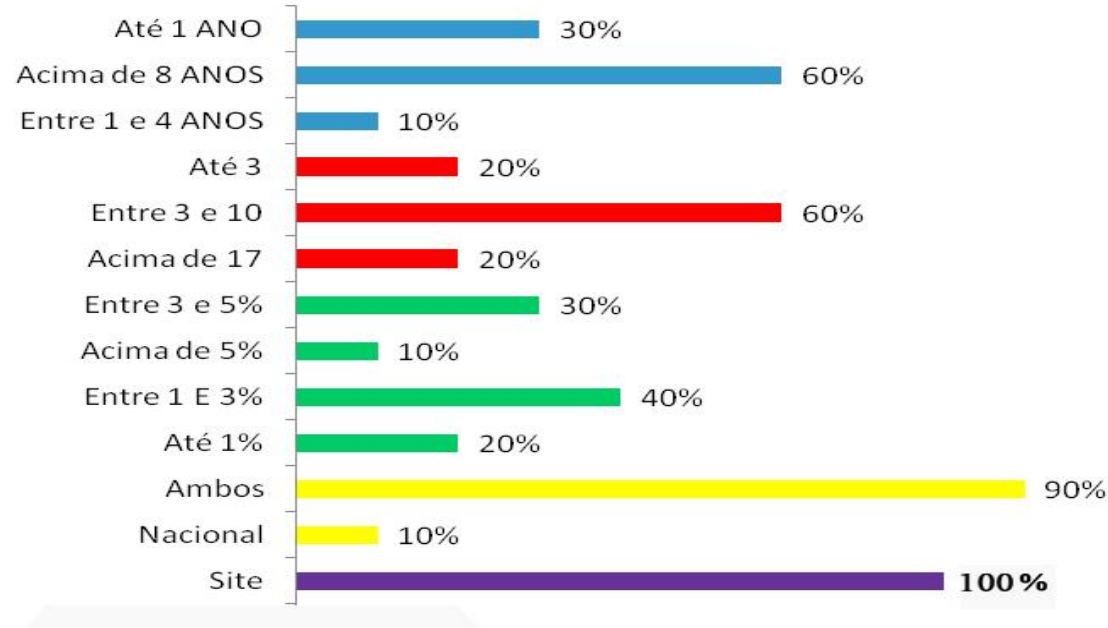

Fonte: Pesquisa de Campo, 2008.

Gráfico 1 - Perfil das Agências de Viagens

De acordo com o Gráfico 1, observa-se o perfil das agências analisadas, no qual se destaca que a grande maioria das organizações investigadas estão atuando no mercado há mais de oito anos, $(60 \%)$ ofertando aos clientes pacotes para destinos nacionais, internacionais, individual e familiar. Observou-se que $60 \%$ das empresas contêm até 10 funcionários. Neste contexto, é importante atentar que $60 \%$ dos investimentos em ações de marketing digital está entre $1 \%$ e $3 \%$ da receita, onde o retorno não depende única e exclusivamente da comunicação, mas de todos os componentes do processo mercadológico da empresa que devem estar coerentes com o objetivos prévios.

As agências de viagens e os profissionais envolvidos com a produção na web vislumbram um nicho de mercado que pode render frutos para seus negócios. A junção de processos bem estruturados e uma equipe alinhada com as características necessárias para se cumprir o papel, são garantias de um alto índice de qualidade de atendimento de uma agência com recursos digitais. Assim, para que ela seja capaz de enxergar o mundo através da ótica dos seus clientes e a partir daí identificar oportunidades que gerem valor, analisando como a marca irá se relacionar com seus consumidores, é necessário entender a internet, também, como um modelo de negócio duradouro. Nos próximos anos conforme cresce o hábito das pessoas em utilizar a internet como uma ferramenta de seus cotidianos, a tendência é o aumento gradual do investimento das grandes empresas em campanhas publicitárias e ações de comunicação no meio. 


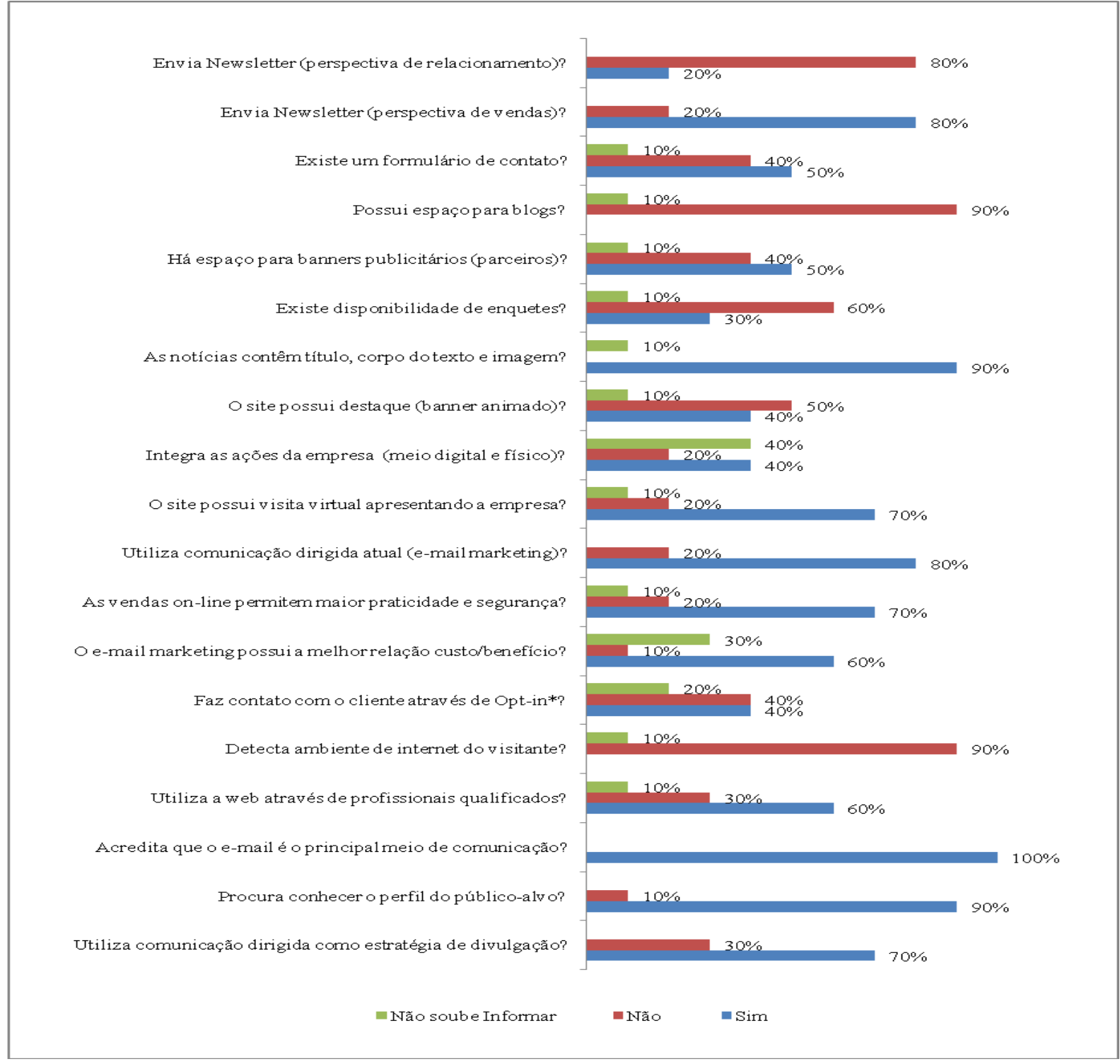

Fonte: Pesquisa de Campo, 2008.

Gráfico 2 - Conhecimento e Utilização de Ferramentas e Estratégias de E-Marketing nas Agências de Viagens

Quando se foca as ações de marketing digital, deve-se atentar que estruturas de serviços como são as agências, carecem de estruturas tecnológicas bastantes dinâmicas. $O$ instrumento de coleta utilizado buscou traçar as percepções dos responsáveis pela gestão do marketing quanto às assertivas apresentadas a estes respondentes. Conforme o gráfico 2 observa-se que a newsletter é mais enfática no contexto da venda de produto com $80 \%$, enquanto $20 \%$ utiliza-se para relacionar-se. Esse dado mostra a preocupação e a eficiência das ações de newsletter ( $e$ mail marketing) voltadas para a venda de produtos. A maioria dos participantes (90\%) respondeu que não tem espaço para blog, isto é, mais da metade não pensou na possibilidade de usar o blog com ferramenta de comunicação com seu público. Verifica-se desta forma, uma oportunidade das organizações utilizarem essa ferramenta como apoio dos serviços pós-venda tendo em vista que pode ser aplicado como um programa interativo com os potenciais clientes, já que é possível adotar o blog como um canal interativo e educativo para o cliente através de materiais informativos com instruções aos consumidores como utilizar da melhor forma produtos e 
serviços ou servir como uma mídia para que outros clientes publiquem suas experiências de consumo.

Praticamente $70 \%$ dos investigados afirmaram se utilizar de ações de comunicação dirigida, ou seja, é evidente a preocupação em trabalhar ações segmentadas, e o marketing digital possibilita gerencialmente. Ao mesmo tempo vale ressaltar que apenas $40 \%$ se utiliza no site da empresa de formas de capturar dados das pessoas que visitam o ambiente digital (contexto de opt-in) assim a organização perde oportunidades de contatos futuros na perspectiva de gerar uma venda ou até fazer parte na mente do navegador-cliente das agências que ele escolhera ao comprar um pacote de viagens.

Quando se trata de comunicação dirigida sua finalidade pode ser de caráter informativo ou impactante, periódico ou sazonal, passivo ou interativo e tudo ao mesmo tempo. Consegue, até mesmo, ser viral e, por seu caráter imediatista, é capaz de causar impacto no público exato, em dias e horários estratégicos. Constata-se nesse sentido o e-mail marketing é complementar a todas as outras mídias (80\%), on-line e off-line, por todos os motivos citados acima. Outra vantagem desta ferramenta envolve seu caráter de direcionar a comunicação exatamente ao público que se quer atingir, ou seja, One to One. Todas as outras formas de comunicação são provocativas (floaters, banners, skyes etc), causam impacto em um prospect, sem uma autorização prévia para receber mensagens sobre aquele tema específico.

Sist. de Navegação Eficiente conforme Largura da Banda

Criação de Projeto através de conhecimento do Público-Alvo

Disposição de Link

"Fale Conosco"

Atendimento em Tempo Real vis ando Agilidade

Notícias em Arquivo

sempre atualizadas

Cores para Indicar os estados dos Links

Mecanis mo de Pesquis a como Elemento mais Importante

Relação Custo/Benefício para Desenv. de Projetos, Vendas e Promoções de Produtos

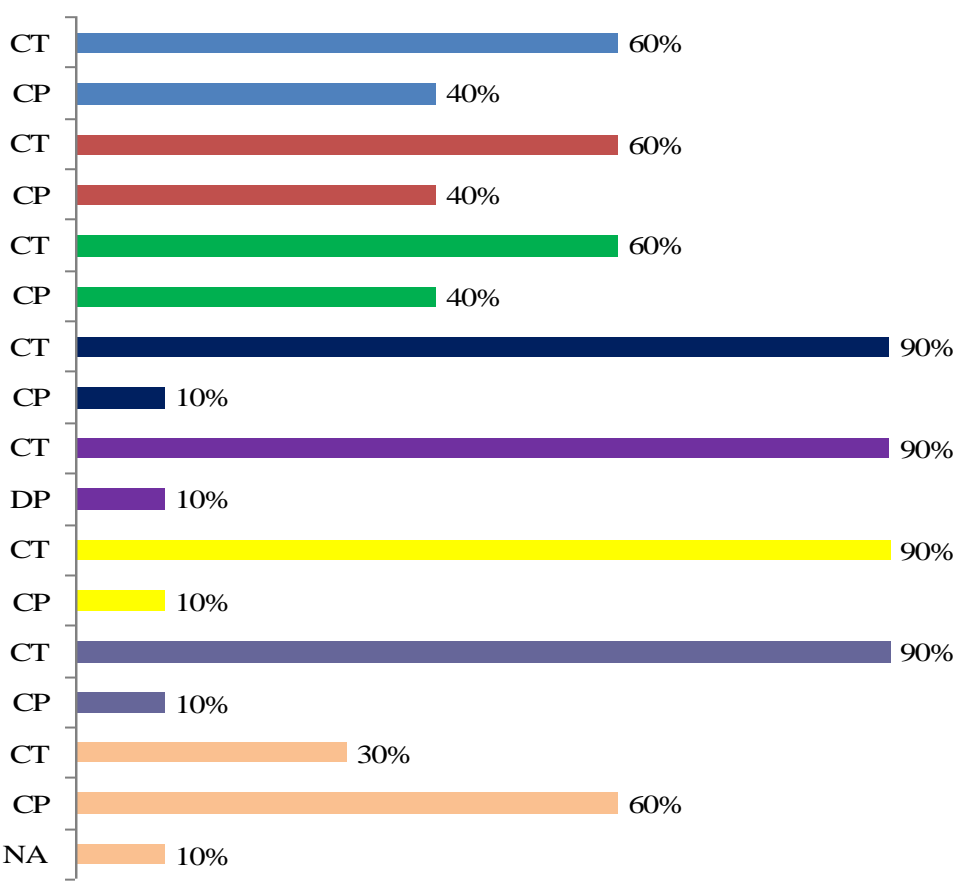

Fonte: Pesquisa de Campo, 2008.

Gráfico 3 - Grau de Concordância Relacionado ao Layout e a Usabilidade do Site 
Com base no gráfico 3, percebe-se que todos os dados abordados nesta pesquisa diante da variável Layout e Usabilidade do Site foram positivos, destacando-se a web como um sistema navegacional no qual o poder dos clientes se manifesta no seu mais alto grau, é visível com média de 60\%. 40\% dos investigados concordam parcialmente ser importante dispor de atendimento em tempo real, isso deve ser observado, pois muitas vezes o consumidor toma decisões com base em informações na ida e navegação no site, perdendo assim esta oportunidade. Independente do design de navegação que escolher para o site há um tema comum a toda navegação: a má arquitetura de informações levará sempre à má usabilidade e a importância de uma estrutura centralizada no usuário é superior do que a arquitetura orientada internamente, mais diretamente, se o cliente não encontrar o produto, ele não o comprará. Para manter o tamanho de páginas pequenas, o número de elementos básicos deve ser reduzido e o efeito de multimídia usado apenas quando realmente ajudar ao usuário a compreender melhor a informação.

Isso mostra que na média geral, para 90\% dos investigados o mecanismo de pesquisa tem relevada importância no uso para ressaltar a atual localização do usuário no site, pois o internauta quando pesquisa algo, está procurando exatamente aquele produto ou serviço que a empresa está oferecendo nos links patrocinados, bem como visualizar o caminho a ser navegado; e para aliar-se a essa ideia usam-se links para resumirem a estrutura do espaço da informação, é útil por ajudar os usuários a aprenderem sobre a estrutura do site e evita que gastem tempo indo a mesma página diversas vezes, facilitando sua compra.

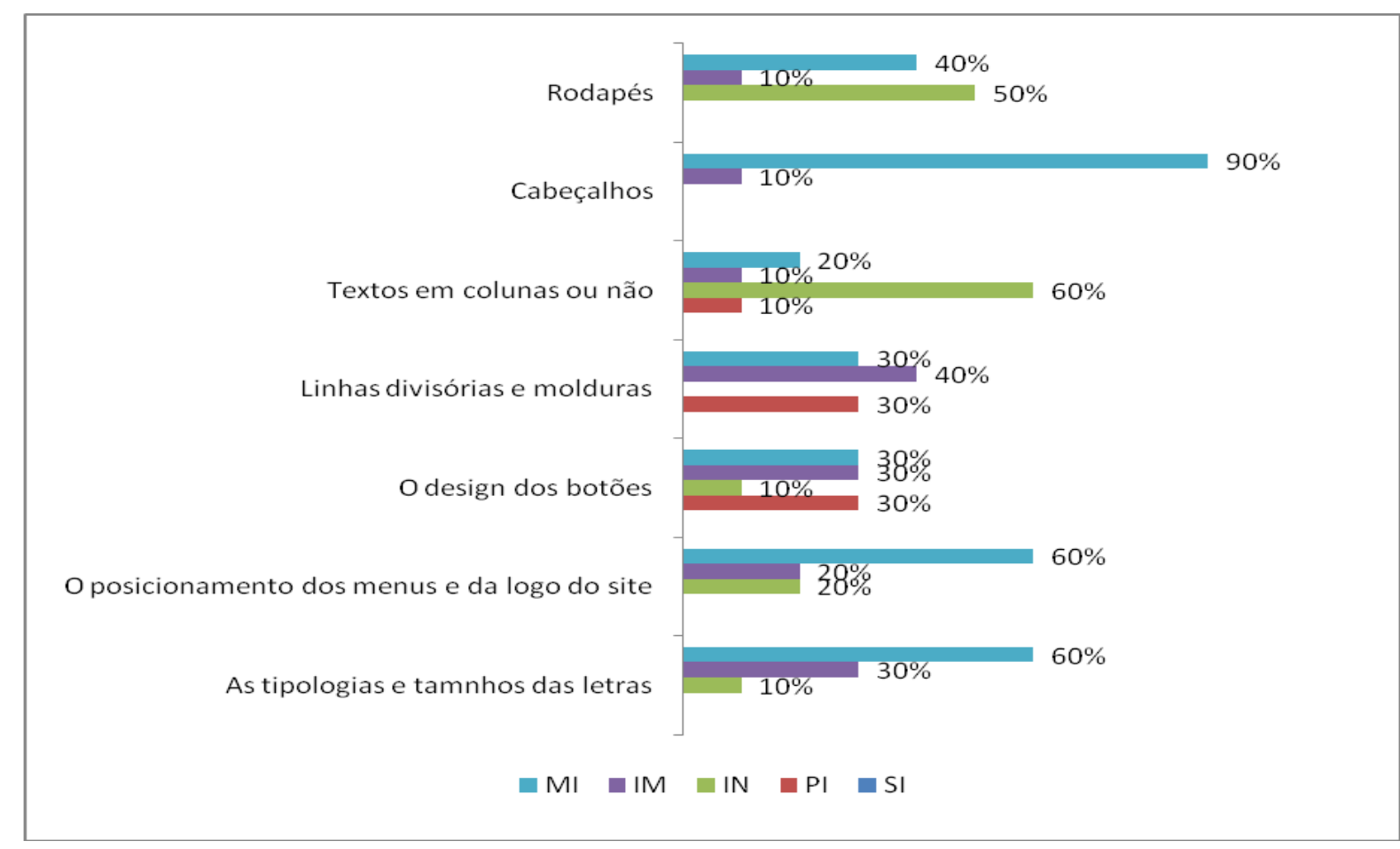

Fonte: Pesquisa de Campo, 2008.

Gráfico 4 - Grau de Importância Relacionado à Identidade Visual do Site das Agências de Viagens

Pode-se afirmar que quando o usuário consegue participar da experiência on-line, a cada clique ele descobre algo novo e isso o impulsiona para outro clique, já fica estabelecida a marca da interação com o internauta. No gráfico 4 se percebeu que para criar ou rever a identidade 
visual de um site, perguntado sobre o posicionamento dos menus e da logo do site, a maioria dos participantes (60\%) respondeu que acham importante a exposição da marca em locais estratégicos. Pensar a arquitetura da navegação para cada perfil de visitante e na facilidade de uso em cada página é condição básica de gerar um cenário de confiança e permanência de mais tempo navegando no mesmo site (REEDY, SCHULLO E ZIMMERMAN, 2001). Com 60\% foi possível aferir a importância na visão dos entrevistados sobre o menu, graficamente bem apresentado, organizado e dispondo de um sistema de navegação dinâmico, de acesso rápido à página principal, e uma estrutura idêntica para todas as páginas do site objetivando facilitar a troca de informações em menor tempo possível. O design é o elemento base que liga todas as fases do processo que em conjunto coerente com uma redação elaborada corretamente, é efetivamente o elemento mais importante para informar o usuário onde ele está, que passo está executando e para onde vai se clicar .o design deve servir a vários objetivos: melhorar a navegação em geral, conquistar novo público, manter o público já fidelizado e permitir que um antigo visitante reconheça ser o mesmo site, porém com uma nova roupagem, como já alertava (KATHERINE, 2012).

\section{Considerações finais}

Através deste estudo de caso analisando as 10 maiores agências de viagens de grande porte de Natal/RN, foi possível identificar como as organizações adotam suas práticas de marketing na web, concomitantemente, verificou-se o perfil destas empresas e quais as principais ferramentas e estratégias são praticadas no mercado para que possam comercializar seus produtos e serviços e gerar ações de relacionamento com o mercado alvo.

Para uma agência conseguir atingir o mais alto nível de qualidade na prestação de seus serviços, ela tem que apresentar-se dinâmica e pronta para atender e cumprir seus objetivos dentro do contexto do marketing na web, além de dispor de ferramentas, auferindo frutos pelo investimento nos mais diversos formatos de comunicação. Enfim, existem investimentos em ações muito duvidosas expostas em grandes portais sem nenhum tipo de segmentação do público-alvo, e quando o fazem, partem do pressuposto da aleatoriedade. Existe um desconhecimento muito grande por parte dos gestores investigados, cuja função é gerir as ações de marketing das empresas sob formas de se obter um relacionamento ativo. As grandes empresas estão investindo parte de seus recursos em links patrocinados, não se preocupando com uma estratégia de posicionamento que a médio/longo prazo apresentará resultados mais expressivos em termos de qualificação de audiência e conseqüentemente na conversão de novos clientes.

No contexto do estudo em tela foi observado que na realidade atual das agências de viagens investigadas existe uma preocupação em sistematizar ações de marketing na web. Entretanto, esta em sua grande maioria na perspectiva da venda simplesmente, isso é um equívoco gerencial, em especial pelo fato da internet fazer parte do processo de decisão de compra de produtos turísticos dos consumidores e dos clientes das agências. Especificamente o Orkut e demais aparatos on-line são totalmente subutilizados. Existe uma preocupação dos sujeitos em adequar o site de acordo com o público alvo, mas como não há um foco no relacionamento, esse mesmo público não serve de bojo de informações para atualizar o sítio. Como este estudo limitou-se a investigar as dez maiores agências de viagem de grande porte da 
cidade de Natal - RN, recomenda-se que sejam feitas futuras pesquisas orientadas para verificar uma amostra maior, detectando desta forma, se há diferenças nas características das empresas e na forma como estas, aplicam suas ações de marketing para web.

\section{Referências}

1. AAKER, David A. Pesquisa de markerting. 2.ed. São Paulo: Atlas, 2010.

2. A LUTA pelos grandes projetos. Revista Webdesign, Rio de Janeiro, v. 4, n. 40, p.30-37, abr. 2007.

3. ANDRADE, Maria Margarida. Introdução à metodologia do trabalho científico. 5. ed. São Paulo: Atlas, 2001.

4. BENI, Mário Carlos. Análise estrutural do turismo. 2. ed. São Paulo: SENAC São Paulo, 1998.

5. BRUNNER Rick E; LELAND, Harden; HEYMAN, Bob. Marketing on-line: estratégias, melhores práticas e estudos de casos. São Paulo: Futura, 2001.

6. BREITENBACH, C. S., e VAN DOREN, D.,C.. Value-added marketing in the digital domain: Enhancing the utility of the internet. The Journal of Consumer Marketing, 15(6), 558-575. http://search.proquest.com/docview/220131671 ?accountid=137015,

1998.

7. CASTELLI, Geraldo. Turismo atividade marcante do século XX. 3. ed. Caxias do Sul: Educs, 1996.

8. CRISOSTOMO, Francisco R. Turismo e hotelaria. São Paulo: Difusão Cultural do Livro, 2004.

9. FIORE, Frank. E-marketing estratégico. São Paulo: Makron, 2001.

10. FOSTER, Douglas. Viagens e turismo. São Paulo: Cetop, 1992.

11. GOELDNER, Charles R; RITCHE, J. R. Brent; MCINTOSH, Robert W. Turismo: princípios, práticas e filosofias. 8. ed. São Paulo: Bookman, 2002.

12. HONORATO, Gilson. Conhecendo o Marketing. Editora Manole, 2004.

13. KATHERINE, T. S. Longitudinal study of digital marketing strategies targeting millennials. The Journal of Consumer Marketing, v. 29, p. 86-92. doi:10.1108/07363761211206339,2012

14. KALAKOTA, Ravi; ROBINSON, Márcia. E business: estratégias para alcançar o sucesso no mundo digital. 2.ed. São Paulo: Bookman, 2001.

15. KENDZERSKI, Paulo. Web Marketing e Comunicação Digital. São Paulo: RR Donnelley Moore, 2005.

16. KOTLER, Philip; KELLER, Kevin. Administração de Marketing. A Bíblia do Marketing. São Paulo: Pearson Hall, 2006.

17. KIANI, G. R. . Marketing opportunities in the digital world. Internet Research, 8(2), 185194. http://search.proquest.com/docview/219868128?accountid=137015, 1998. 
18. LICKORISH, Leonard; JENKINS, Carson L. Introdução ao turismo. Rio de Janeiro: Campus, 2000.

19. Lazaroiu, G. . Social media, networking software, and creative digital marketing. Review of $\begin{array}{lll}\text { Contemporary } \quad \text { Philosophy, 160-165. } & \text { 9, }\end{array}$ http://search.proquest.com/docview/820913744?accountid=137015,2010

20. MALHOTRA, Naresh K. Pesquisa de marketing: uma orientação aplicada. 3. ed. Porto Alegre: Bookman, 2004.

21. OLIVEIRA, Silvio Luiz de. Tratado de metodologia científica. São Paulo: Pioneira, 2002.

22. REEDY, Joel; SCHULLO, Shauna; ZIMMERMAN, Kenneth. Marketing eletrônico: a integração de recursos eletrônicos ao processo de marketing. São Paulo: Bookman, 2001.

23. REJOWSKI, M. Ensino em Turismo no Brasil: Reflexões sobre a realidade do ensino de

24. graduação de 1970 a 2000. In: REJOWSKI, M.; BARRETTO, M. (orgs.). Turismo:

25. Interfaces, Desafios e Incertezas. Caxias do Sul: EDUCS, 2001, cap.3, p. 47-56.

26. ZEITHAML, Valarie A. Marketing de Serviços: a empresa com foco no cliente. 5ạed. Porto Alegre: Bookman, 2011.

27. ZENONE, Luiz Claudio. CRM - Customer Relationship Management: gestão de relacionamento com o cliente e a competitividade empresarial. São Paulo: Novatec Editora, 2007. 